Available online at GSC Online Press Directory

GSC Biological and Pharmaceutical Sciences

e-ISSN: 2581-3250, CODEN (USA): GBPSC2

Journal homepage: https://www.gsconlinepress.com/journals/gscbps

(RESEARCH ARTICLE)

\title{
Best interests of the future child in ART; not well served by legislation
}

\author{
Van Keppel Margaret ${ }^{1}$ and Yovich John L 2,3,* \\ ${ }^{1}$ Psychologist \& Counsellor, PIVET Medical Centre, Perth, Western Australia, Australia 6007 \\ 2 Medical Director, PIVET Medical Centre, Perth, Western Australia, Australia 6007. \\ ${ }^{3}$ School of Pharmacy and Biomedical Science, Curtin University, Perth, Western Australia, Australia.
}

Publication history: Received on 10 June 2020; revised on 19 June 2020; accepted on 21 June 2020

Article DOI: https://doi.org/10.30574/gscbps.2020.11.3.0172

\begin{abstract}
Probably most personnel working within assisted reproductive technology (ART) have occasionally held concerns about a patient's capacity to parent. This raises the question of responsibilities under the principle of the "best interests of the child". This principle has long been enshrined in advisory guidelines as well as legislation, as though the meaning and intent are self-evident. Whilst its intent is laudable, its application is problematic. Clinical practice is patientcentred, and ART personnel are highly responsive to the desire and sense of immediacy of the infertile woman (or couple) for a child. However, over a 39-year period, our clinic has faced a number of challenging patient presentations, causing serious concerns about the potential implications and/or risks to a child conceived by ART and creating the dilemma: do we treat, or not treat? Drawing on these examples, this paper discusses the nature of "the principle", from a variety of perspectives. It considers that the best interests of the future child are served by addressing the medical and psychosocial concerns of the potential mother, rather than engage with the ill-defined and poorly understood principle of "the best interests of the child" in legislation and deny her the opportunity for motherhood based on a perception of an unfavourable environment for a future child.
\end{abstract}

Keywords: Assisted Reproductive Technology ART; Donor gamete ethics; Donor embryo Ethics; Surrogacy ethics; In Vitro Fertilization IVF; ART ethics; ART legislation; Social responsibility

\section{Introduction}

The overriding motivation for those personnel involved in the field of assisted reproductive technology (ART) is to assist people achieve their desire of parenting healthy children. Such is a basic medical tenet; yet authoritative bodies and legislation invariably indicate the overriding principle must protect the "best interests of the child" - who is yet to be conceived. However, it is our observation that, in contemporary practice, many clinical practitioners struggle to understand what it really means from both conceptual and operational perspectives. Hence, the principle remains poorly defined and often "overlooked". ART is primarily patient-centred in that clinicians respond to the strong desire of women (and couples) for a child, along with their sense of immediacy. Nonetheless, longstanding practitioners in ART will undoubtedly have been tested by a wide range of confronting scenarios that challenge interpretation of the phrase "the best interests of the future child". Clinico-social decisions will likely be based on the moral and ethical principles of the individual practitioners. Consequently, the decision "not to treat" may be made inconsistently, certainly against the interests of the patients, and probably against the philosophical evolution of modern times, progressing towards the concept of "all life opportunity is better than no life", especially when conception outside ART requires no approval. We address this topic using clinical and conceptual material from an Australian perspective and identify ways in which ART practice may better address the interests of the future child without discrimination to patients. We conclude that the principle is not an appropriate clinical guide and should be removed from legislation, Codes of Practice (COP) and Practice Guidelines.

\footnotetext{
* Corresponding author: Yovich John L
} 


\section{Material and methods}

PIVET Medical Centre has been operational since 1981 and is one of the pioneer ART facilities with first child born from In Vitro Fertilization (IVF) in July 1982 [1,2]. Clinical practice was conducted under the general Rules of the West Australian (WA) Medical Act 1884 and the guidelines of the National Health and Medical Research Council (NHMRC) [3]. Specific legislation governing ART was introduced in 1991 as the Western Australian Human Reproductive Technology Act (1991) [4]. Initially it required that only legally married couples (or those in at least a 5-year de-facto marriage) could access ART procedures. Couples had to be hetero-sexual with proven infertility, from causes not due to age. Public appeal eventually led to amendments e.g. single women and lesbian couples could access ART in 2002 and the procedures could be applied for genetic screening in 2004 thereafter accepting non-commercial Surrogacy in 2008.

However, despite the amendments, the Act continues to prescribe that community attitudes and expectations must be considered (Section 4) and 4 essential criteria must be addressed (Section 23). Those specific criteria state that:

- The interests of the (yet to be born) infant are paramount

- The risks to the woman and her existing family must be considered

- That support resources must be considered, particularly for single women

- Women cannot be treated if the infertility is caused by age (later, in 2003, "age" defined as menopause when this occurs after age 45 years)

Australia comprises six States and Territories and ART facilities are variably subject to respective State Legislation which can be nil, minimal or wide-ranging as in Western Australia, Victoria and South Australia. Federal jurisdiction (Commonwealth of Australia) has no specific legislation concerning ART issues, apart from a temporary ban on Cloning procedures (planned for repeal).

PIVET has encountered a number of occasions when it has faced clinical scenarios which could breach the legislation, and these are presented in the next section (Results).

\section{Results}

Whilst only a minute proportion of PIVET patients have presented with challenging issues, they nonetheless leave the counsellor and staff questioning whether they personally and/or the ART Clinic, should treat, or not treat them. Table 1 (Column: Scenario) identifies 11 types of challenging issues, comprising 40 patients which we have encountered in our practice over the past 39 years (Column: Detail), and includes 2 patients with histories of infanticide, others where the partner had indictable offences and others where the woman or the couple have had a previous determination of incapacity to parent. Individual case details are inappropriate in this setting as explicit detail can breach confidentiality requirements. From a total patient caseload of more than 30,000 couples, these 40 cases have all caused staff members to express concern about possible outcomes including both welfare of ensuing children as well as vulnerability of the ART clinic to provisos within legislation. Conversely, any decision not to treat raises the question of unfair discrimination, or even a legal challenge on the rights of an ART clinic to deny anybody access to treatment on nonmedical grounds. As can be seen from Table 1 (Column: Outcome) in more than half of the scenarios treatment did not progress, mostly as a patient decision following the extensive and protracted counselling processes, although PIVET, (after extensive consideration including psychiatric and external psycho-social consultations, which were not supportive) declined to treat either of the women who had a history of infanticide. Each was a single woman who had wanted to use their cryopreserved sibling embryos to have further children. One of the women was single as her husband had died following the death of the first child (conceived from IVF). PIVET could not be satisfied that history might repeat in these case scenarios. 
Table 1 Examples of challenging issues from actual patient presentations

\begin{tabular}{|c|c|c|}
\hline Scenario & Detail & Outcome \\
\hline $\begin{array}{l}\text { Non-paternal } \\
\text { Partner }\end{array}$ & $\begin{array}{l}\text { Male partners wish to "donate" sperm for female } \\
\text { partner's use so that they have no legal or parenting } \\
\text { responsibilities, no plans to be on a child's birth } \\
\text { certificate. Wish to be less involved in a future child's } \\
\text { life because of commitments to existing children from } \\
\text { a previous relationship, and/or not interested in } \\
\text { fathering given their advanced age. }\end{array}$ & $\begin{array}{l}1 \text { male partner declined to consent; } \\
\text { following further consideration, female } \\
\text { withdrew from treatment. } \\
1 \text { male partner agreed to continue with } \\
\text { treatment, still reluctant to support any } \\
\text { future child, couple recommended to } \\
\text { seek independent legal advice. }\end{array}$ \\
\hline $\begin{array}{l}\text { Previous } \\
\text { Infanticide }\end{array}$ & $\begin{array}{l}\text { Requests for ART, including anonymously donated } \\
\text { sperm, following the deaths of previous children } \\
\text { through infanticide. Earlier diagnoses of post-partum } \\
\text { psychosis. }\end{array}$ & $\begin{array}{l}\text { Treatment declined, following } \\
\text { extensive consideration }\end{array}$ \\
\hline $\begin{array}{l}\text { Inability to Care } \\
\text { for Existing } \\
\text { child(ren). }\end{array}$ & $\begin{array}{l}\text { Existing child of potential patient in long term foster } \\
\text { care, following sustained period of poor mental health } \\
\text { and inability to care for child. }\end{array}$ & $\begin{array}{l}\text { Interest in treatment waned as } \\
\text { assessment progressed. With one } \\
\text { particular patient, psychiatrist advised } \\
\text { against necessary change in } \\
\text { psychotropic medication and further } \\
\text { pregnancy. }\end{array}$ \\
\hline $\begin{array}{l}\text { Intimidating } \\
\text { Demeanour }\end{array}$ & $\begin{array}{l}\text { Graphic tattoos depicting violent acts. } \\
\text { Inappropriate and anti-social interactions between } \\
\text { the patients and towards staff. } \\
\text { Members of out-law motor- cycle gangs. }\end{array}$ & $\begin{array}{l}\text { Patients did not follow through with } \\
\text { treatment, of own volition. One patient } \\
\text { was requested to refrain from } \\
\text { intimidating behaviour toward staff, } \\
\text { also withdrew from treatment. }\end{array}$ \\
\hline $\begin{array}{l}\text { Unusual, Adult- } \\
\text { Centred Reasons } \\
\text { for Childbearing }\end{array}$ & $\begin{array}{l}\text { Patients have explicitly volunteered reasons such as: } \\
\text { to be cared for in old age, a need for a son, to be able to } \\
\text { remain in Australia. }\end{array}$ & Treatment progressed. \\
\hline $\begin{array}{l}\text { Recent Death of a } \\
\text { Child }\end{array}$ & $\begin{array}{l}\text { Requests for ART, including gamete donation, where } \\
\text { the patients are still actively mourning the loss of a } \\
\text { child. }\end{array}$ & Treatment progressed. \\
\hline $\begin{array}{l}\text { Incarcerated } \\
\text { Partner }\end{array}$ & $\begin{array}{l}\text { Partners are serving long term prison sentences for } \\
\text { indictable offences. }\end{array}$ & Treatment not feasible. \\
\hline $\begin{array}{l}\text { Psychiatric } \\
\text { Histories }\end{array}$ & $\begin{array}{l}\text { Extensive periods in inpatient psychiatric care, on } \\
\text { anti-psychotic medication. Associated inability to care } \\
\text { for child from previous relationship. }\end{array}$ & $\begin{array}{l}\text { Psychiatrist advised against necessary } \\
\text { change in psychotropic drugs and } \\
\text { further pregnancy. }\end{array}$ \\
\hline $\begin{array}{l}\text { Second-Chance } \\
\text { Requests after } \\
\text { Terminations }\end{array}$ & $\begin{array}{l}\text { Couples who had previously terminated ART } \\
\text { pregnancies, re-presenting for further treatment, } \\
\text { when their circumstances had changed (marital } \\
\text { reconciliation, improved finances). }\end{array}$ & $\begin{array}{l}\text { Treatment progressed, albeit some } \\
\text { clinic staff declined to be involved with } \\
\text { treatment. }\end{array}$ \\
\hline $\begin{array}{l}\text { History } \\
\text { of } \\
\text { Indictable } \\
\text { Criminal } \\
\text { Offence(s) }\end{array}$ & $\begin{array}{l}\text { Drug trafficking and importation. } \\
\text { Child sexual abuse (CSA) }\end{array}$ & $\begin{array}{l}\text { Treatment unable to progress with one } \\
\text { couple because partner incarcerated. } \\
\text { Knowledge of previous CSA history not } \\
\text { known until treatment concluded, } \\
\text { treatment was unsuccessful. }\end{array}$ \\
\hline $\begin{array}{l}\text { Terminal illness } \\
\text { of male }\end{array}$ & $\begin{array}{l}\text { Male partner diagnosed with a terminal illness; female } \\
\text { partner and sometimes other family members (e.g. } \\
\text { mother of male patient) are keen to create } \\
\text { embryos/have child, male less interested. }\end{array}$ & $\begin{array}{l}\text { Treatment progressed following } \\
\text { further counselling and informed } \\
\text { consent of male partner. }\end{array}$ \\
\hline
\end{tabular}

Our clinic has on 2 occasions in 2003 faced the Reproductive Technology Committee (created under the WA HRT Act 1991) for successfully treating patients deemed "not eligible" under Section 23 of the Act. These were women aged 47 years and 49 years, respectively, who were accessing donor oocytes. Fortunately, the clinic received the lowest penalty, 
being a reprimand; probably because no persons actually suffered in any way, the resulting children are healthy, and the parents to this day are very happy indeed, completely unaware of their cases being the subject of legal challenge.

Conversely, occasional patients who were concerned that they may be denied treatment have threatened to challenge the clinic under provisions embraced by the Equal Opportunity Act 1984, the Age Discrimination Act 1984, and the Sex Discrimination Act 1984, but none proceeded following legal advice to them that the most recent Act (WA HRT Act 1991) with its amendments, prevails. Table 1 (column: Outcome) shows that treatment was declined outright by the clinic in only one scenario - involving infanticide of a previous ART infant and where psychiatric opinions were not clearly supportive. However, the deliberations on other case scenarios were often protracted and other psycho-social issues impacted, including divorce and single status.

\section{Discussion}

The main tenet of the West Australian (WA) Medical Act 1884 indicates that doctors should apply their knowledge and skills to alleviate disease and discomfort of all patients, without discrimination. Furthermore, formal psycho-social counselling has been an imperative from the outset at PIVET Medical Centre, a private ART clinic operating in WA since 1980.

Initially, ART clinics developed clinical practices from ideas presented at proceedings of the Fertility Society of Australia (FSA), which evolved during the early 1980's as the peak body representing scientists, doctors, researchers, nurses, consumers, and counsellors in reproductive medicine in Australia \& New Zealand (ANZ). Today, subgroups include IVF Directors, Fertility Nurses Association (FNA), Scientists in Reproductive Technology (SIRT), ANZ Infertility Counsellors Association (ANZICA) [5], and Australia's national consumer infertility support network (ACCESS).

\subsection{Community attitudes}

During the 1980's, public anxieties about the emerging ART processes were expressed through news media, notably newspapers, tabloid magazines, and television. The FSA responded by creating a self-regulatory supervisory body known as the Reproductive Technology Accreditation Committee (RTAC) in 1986, and which has increasingly tightened practices around a Code of Practice (COP) [6]. However, some Australian states felt impelled to introduce specific legislation, in particular Victoria (Infertility [Medical Procedures] Act 1984) and WA (Human Reproductive Technology Act, 1991). The former has since come under control of the Victorian Assisted Reproductive Treatment Authority (VARTA) following revised legislation; the Infertility Treatment Act 1995.

Historically, the "best interests of the child" principle has mostly been applied in relation to the implications for the child of "donor conception", being a somewhat limited interpretation in the context of ART. Where RTAC (self-regulatory) and legislation (statutory) do actually concur is with respect to psycho-social counselling, which is encouraged for all patients and is mandatory for any cases involving donor gametes or embryos as well as for surrogacy arrangements. Counselling is not mandatory for heterosexual couples using their own gametes, but it is encouraged for all patients embarking on fertility treatment. In practice, all new PIVET patients presenting for IVF are encouraged to see the counsellor for a session, at no cost to themselves, to assist with their preparation for treatment. Some patients may decline such counselling, usually welcoming it later if treatments are unsuccessful or pregnancies suffer complications. Counsellors do not have a mandate to assess patients' suitability for parenthood but do provide advice to both patients and the Medical Director regarding psycho-social management implications.

\subsection{Code of Practice; COP}

It appears a universal imperative in ART that the "best interests of the child" should be observed by facilities and practitioners. The ESHRE Task Force on Ethics and Law provides eight recommendations [7]; the first being that "the fertility specialist should refuse to collaborate in the parental project if he/she judges that there is high risk of serious harm to the future child."

The concept of "the best interests of the child" has been widely discussed and applied in the child welfare sector, over a very long period, particularly in relation to making decisions as to the care needs of existing children who have been abused and/or neglected. Of note is the work of Goldstein, Solnit, Goldstein and Freud (1996) "The best interests of the child: The least detrimental alternative". They assert that professionals need to be aware of the limits of their training, knowledge and expertise and refrain from making decisions that have profound consequences without the qualifications to make them. Further, that it is inherently difficult, and undesirable, to perform more than one role with a patient/person, where these roles are incompatible (e.g. supportive and investigative roles). These points, we believe, are also relevant to the application of the concept in ART [8]. 
The COP of RTAC [6] has specific reference to the reproductive health of infertile men and women but is silent with respect to any reference to the future child. However, the ANZICA mission statement indicates "...ANZICA counsellors strive to support and benefit those individuals with whom they work, including the welfare and best interests of any potential unborn child." Section 23 of the WA HRT Act 1991 [4] specifically states that the interests of the future infant are paramount. The NHMRC ethical guidelines for the clinical practice of ART, which underpins both RTAC and Western Australian Legislation, under Section 5 states "Clinical decisions must respect, primarily, the interests and welfare of the persons who may be born".

\subsection{Penalties for breeches of the legislation}

Under the West Australian legislation, penalties are directed at both the IVF Facility (the Corporation) as well as to key staff (Medical Director, Laboratory Director, Nursing Director) and Consultant Clinical staff (Doctors, Counsellors). The penalties include hefty fines to the Corporation and to individuals, with prison sentences ranging from 2 to 15 years, mostly applied to the Medical Director. The higher prison sentences relate to significant breaches of confidentiality and failure to maintain the mandatory standards dictated under the COP, a process which is evaluated annually by both the RTAC (national self-regulatory body) as well as by the RTC (acting under statutory control - the WA HRT Act 1991). Ultimate responsibility under both systems is sheeted to the Medical Director who requires to be a practicing Obstetrician \& Gynaecologist in good standing with the Royal Australian and New Zealand College of Obstetricians and Gynaecologists (RANZCOG) and with additional higher qualification such as the RANZCOG certification in Reproductive Endocrinology and Infertility (CREI). Extensive experience in ART is also required for aspiring applicants to this Medical directorship role.

However, in the 29 years since introduction of the legislation, we are aware that the only penalties applied have been the 2 cases of "reprimand" directed to our clinic. This implies that the Legislation is rather redundant as the structure of ART facilities and the RTAC accreditation system suffices to prevent any serious problems arising. In fact, ART Clinics throughout Australia and New Zealand maintain a low public profile despite the complexity of the work program and the variable clinical and socio-psychological patient profiles presenting for treatment. The Australia and New Zealand Database (ANZARD) reports annually and indicates that 91 ART facilities undertook a total 82,215 treatment cycles in the year 2017 [9]. The majority utilized their own gametes with 47,545 autologous IVF cycles initiated had fresh embryo transfers and 29,808 had autologous thaw cycles. There were 3,316 cycles involving recipients of donor oocytes or embryos and 2,984 cycles involved donor sperm. Gestational surrogacy treatments (meaning IVF with gametes from the commissioning couple or their donors) were conducted in 364 treatments. This profile occurred without any public revelations of adverse events and, in itself, indicates that the presence of legislative "controls" in some Australian States had no bearing on the outcomes and can be considered irrelevant.

\subsection{Facing potential risk issues for the ensuing child}

From a micro-perspective, some risk factors have been identified as holding the potential to compromise the "best interests" of a prospective child and include: criminal convictions that are the result of violence, abuse or exploitation (especially if they involve a child, although not exclusively), medical histories that may impact on a person's capacity to parent a young child to adulthood, significant psychiatric histories and current psychological functioning, history of alcohol and drug abuse and dependency, unavailability to parent (e.g. an incarcerated partner), and serious instability in the relationship between partners. Further, in relation to the use of donor gametes, donor embryos, and surrogacy, a demonstrated interest and capacity to accept and facilitate an offspring's access to information about themselves, including the maintenance of ethnic and cultural continuity, is believed to also reflect the best interests of the prospective child.

Much of the discussion, debate, interpretation, and application of "the principle" within the ART context has been primarily concerned with donor conception, including the needs/rights of donor-conceived offspring to access information about their donors, the posthumous use of gametes and embryos, and access to ART by those in nontraditional family relationships, such as single and lesbian women, being not affected by infertility due to a medical cause $[10,11]$. It appears that the impetus towards legislation comes from such issues and the resultant need to define ownership of embryos in situations of separation and divorce. However, we take the view that Section 23 of the WA HRT Act 1991 is redundant, that doctors and health professionals in Australia do not need such provisions to provide medical services embraced by ART.

\subsection{Morals, ethics, and ART}

Respected modern philosophers can now project fewer laws and religious tenets controlling everyday lives [12], as well as regulating eligibility for ART procedures $[13,14]$. This process of reducing constraints, whilst rapidly evolving, may 
not yet have reached the position of "does anything matter" as espoused by Australian philosopher Peter Singer [15]. Couples can conceive outside ART clinics at their personal whim, so why should ART conceptions carry any regulation, regardless of the potentially unfavourable circumstances into which the child might be delivered? All life is better than no opportunity for life, states one esteemed philosopher [16], so how far should ART professionals have to worry about the domestic circumstances into which a child is born?

\subsection{Protecting Children}

There are multiple conventions, charters, and treaties that address the matter of the rights of all persons, including children. The legal rights of children have been well documented by Claire Breen [17] from the School of Law, Waikato, New Zealand. These rights embrace the imperative that all persons should be afforded dignity, equality, and freedom; and further, that the impacts of science and technology, including medicine, must not undermine these rights. The human rights that are relevant to ART include a right to safety from physical and mental abuse, a right to family relationships, knowledge of parentage, and a right to information about one's self.

Table 2 The UN Convention on the Rights of the Child: The right to life.

\begin{tabular}{|l|}
\hline To be raised by his or her parents within a family or cultural grouping. \\
\hline A relationship with both parents even if they are both separated. \\
\hline To be protected from abuse, physical and mental violence, or exploitation. \\
\hline Protection of their privacy. \\
\hline The right to express their opinions, and for these opinions to be heard and acted upon when appropriate. \\
\hline $\begin{array}{l}\text { The right to have separate judicial representation in any judicial dispute concerning their care, and that } \\
\text { their viewpoint be heard in such cases. }\end{array}$ \\
\hline To have access to vital information about themselves. \\
\hline $\begin{array}{l}\text { That all actions concerning children, directly or indirectly, whether undertaken by public or private bodies, } \\
\text { the best interests of the child shall be of primary consideration. }\end{array}$ \\
\hline
\end{tabular}

The UN Convention on the Rights of the Child [18] identifies a number of basic rights relevant to this discussion and these are summarised in Table 2. The Children and Community Services Act, WA [19] states that the best interests of the (existing) child are paramount and that there is a responsibility to determine that every child will have safe, secure, and stable relationships and living arrangements. Furthermore, that their parents are capable of protecting them from harm and to provide for their needs. Finally, that their familial, ethnic, and cultural continuity will be maintained.

\subsection{The principle of "best interests of the child"}

In developing the principle of "the best interests of the child", the West Australian Human Reproductive Technology Act, 1991 [4] reads: "That the prospective welfare of any child to be born consequent upon a procedure to which this Act relates is properly taken into consideration". In order to determine how "the principle" was interpreted and practiced, ART legislation was examined in 3 Australian states [20], and a qualitative study of ART counsellors from 2 Australian states, along with New Zealand, was subsequently undertaken [21]. Surprisingly, both surveys report wide disparities in how "the principle" is both understood and applied by ART practitioners. These studies concluded that "the principle" is undermined when there are few effective and inadequate systems in place that allow the well-being of the child to be actually addressed, as it needs to be when a practitioner is challenged by a prospective patient's presentation [22].

The ART clinic then finds itself treading the narrow path between compliance with the COP of RTAC and avoiding the challenge of unfair discrimination from angry patients. The current, 6th iteration of the COP of RTAC no longer uses the term "paramount" or refers to "the principle", simply indicating that children born through ART have rights to know their genetic origins and health risks [6].

Similar to Western Australia, Victoria has specific eligibility criteria enshrined in legislation (VARTA) and goes further in requiring a police clearance to identify any criminal record and/or child protection orders. If a patient is deemed to not meet the eligibility criteria, they can appeal an ART facility's decision not to treat them through a Patient Review Panel. Such an external model of judgement may seem ideally non-prejudicial, but for ART clinics in other states of 
Australia, the final judgement of eligibility for treatment rests with an internal model headed by the Medical Director, who will generally seek opinions and reports from fertility counsellors, other clinicians, independent psychologists and psychiatrists, and even relationship counsellors if deemed to be relevant. This means the focus is on appropriate medical management of the woman or couple seeking fertility treatment rather than the "best interests" of the "yet-to-beconceived' child [23]. It accords with the views of Daniels et al [11] who state that the principle of paramountcy for the best interests of the child, whilst well-meaning and useful, is very difficult to action because of the complex and changing conditions and demands of ART, the interplay between professionals, parents, and state, and finally because it is very difficult to define and enact. Taken together these esteemed views have led to revised thinking about applying legislation to allay community fears concerning the best interests of future children arising from assisted reproduction $[24]$.

\section{Conclusion}

ART professionals are primarily motivated by the desire to help patients to conceive a healthy child; but there is also a responsibility to be aware of any presentation or information that identifies any risk factor(s) that may compromise the well-being of a future child. The idea of paramountcy concerning the "best interests of the (future) child" is, in our opinion, an inappropriate concept, beyond the ability of ART professionals to decide without obvious discrimination. Having the "best interests of the child" enshrined in ART legislation is inappropriate, difficult to operationalise, risks creating vexed and possibly discriminatory decision-making and is a source of intimidation for ART clinical staff, particularly the Medical Director who faces the major impact of penalties under the jurisdiction. ART experts across an international perspective strongly believe that legislation in this area is completely unnecessary and should be repealed; self-regulation has shown itself appropriate to the task of protecting the best interests of the future children.

\section{Compliance with ethical standards}

\section{Acknowledgments}

We are grateful to Australian philosopher and bioethicist, Julian Savulescu for advising us on our earlier manuscript, following which we made significant adjustments. Julian is Uehiro Professor of Practical Ethics at the University of Oxford. He also directs the Oxford Centre for Neuro-ethics and the Institute for Science and Ethics.

\section{Disclosure of conflict of interest}

This is a self-funded publication from the authors. John Yovich is Medical Director and Margaret Van Keppel is the psycho-social Counsellor at PIVET Medical Centre. Each of the patients included in Table 1 was clinically managed by both authors. There are no conflicts of interest to declare by either author.

\section{Statement of ethical approval}

The present research work does not contain any studies performed on animals or human subjects by either of the authors. The clinical scenarios have all been conducted under approved protocols and have been presented here in generic form to protect patient confidentiality. This complies with requirements of the Curtin University HREC (Human Research Ethics Committee) approval RD-25-10 (2015) for the analysis and presentation of retrospective data from the PIVET Medical Centre.

\section{Statement of informed consent}

Appropriate informed consent was obtained from all individual participants included in this study. These consents are specifically approved and monitored under both national (RTAC) as well as State (RTC) surveillance.

\section{References}

[1] Yovich JL and Craft IL. (2018). Founding pioneers of IVF: Independent innovative researchers generating livebirths within 4 years of the first birth. Reprod Biol, 18, 317-323.

[2] Yovich JL. (2020). Founding pioneers of IVF Update: Independent innovative researchers generating livebirths within 4 years of the first birth. Reprod Biol, 20, 111-113.

[3] NHMRC. (2017). Ethical guidelines on the use of assisted reproductive technology in clinical practice and research. Australian Government: National Health and Medical Research Council Document, 104. 
[4] Human Reproductive Technology Act. (1991). (Western Australia), 156.

[5] Fertility Society of Australia. (2016). ANZICA, "Mission and Goals" "The best interests of the child: The least detrimental alternative", 10.

[6] Fertility Society of Australia. (2015). Code of practice for assisted reproductive technology units; Reproductive Technology Accreditation Committee, 30.

[7] Pennings G, de Wert G, Shenfield F, Cohen J, Tarlatzis B and Devroey P. (2007). ESHRE Task Force on Ethics and Law: the welfare of the child in medically assisted reproduction. Hum Reprod, 22, 2585-2588.

[8] Goldstein J, Solnit AJ, Goldstein S and Freud A. (1998). The Best Interests of the Child: The Least Detrimental Alternative. Simon and Schuster, New York, 352.

[9] Newman JE, Fitzgerald O, Paul RC and Chambers GM. (2019). Assisted reproductive technology in Australia and New Zealand 2017. Sydney: National Perinatal Statistics Unit, the University of New South Wales, Sydney, 83.

[10] Blyth E and Cameron C. (1998). The welfare of the child: An emerging issue in the regulation of assisted conception. Hum Reprod, 13, 2339-2355.

[11] Daniels K, Blyth E, Hall D and Hanson K. (2000). The best interests of the child in human reproduction: The interplay between the state, professionals and parents. Politics Life Sci, 19, 33-44.

[12] Parfit D. (2011).On what matters, Volumes 1 and 2. Oxford University Press, 1440.

[13] McMillan J. (2014).Making sense of child welfare when regulating human reproductive technologies. J Bioeth Inquiry, 11, 47-55.

[14] Lee E, Macvarish J and Sheldon S. (2014). Assessing Child Welfare under the Human Fertilisation and Embryology Act 2008: A Case Study in Medicalisation? Sociology of Health and Illness, 36, 500-515.

[15] Singer P. (2011) "Does Anything Matter?" Australian Broadcasting Corporation; Religion and Ethics.

[16] Robertson JA. (2004). Procreative liberty and harm to offspring in assisted reproduction, 30, 7-40.

[17] Breen C. (2001). Poles apart? The best Interests of the child and assisted reproduction in the antipodes and Europe. International J Child Rights, 9, 157-180.

[18] United Nations Convention on the Rights of the Child. (2015).

[19] Children and Community Services Act, 2004, (Western Australia). (2015). Best interests of child are paramount consideration, 6(7), 8.

[20] Thorpe R, Croy S, Petersen K and Pitts M. (2012). In the best interests of the child? Regulating assisted reproductive technologies and the well-being of offspring in three Australian states. Int J Law Policy Family, 26, 259-277.

[21] De Lacey SL, Peterson K and MacMillan J. (2015). Child interests in reproductive technology: how is the welfare principle applied in practice? Hum Reprod, 30, 616-624.

[22] Stern JE, Cramer CP, Green RM, Garrod A and DeVries KO. (2003). Determining access to assisted reproductive technology reactions of clinic directors to ethically complex case scenarios. Hum Reprod, 18, 1343-1352.

[23] Pennings G. (1999).Measuring the welfare of the child: in search of the appropriate evaluation principle. Hum Reprod, 14, 1146-1150.

[24] Yovich JL, Casper R, Chapman M, Tesarik J and Anderson RA. (2019). Regulating ART: time for a re-think in the light of increasing efficacy, safety and efficiency. Reprod Biomed Online, 38, 483-486.

\section{How to cite this article}

Van Keppel M and Yovich JL. (2020). Best interests of the future child in ART; not well served by legislation. GSC Biological and Pharmaceutical Sciences, 11(3), 189-196. 